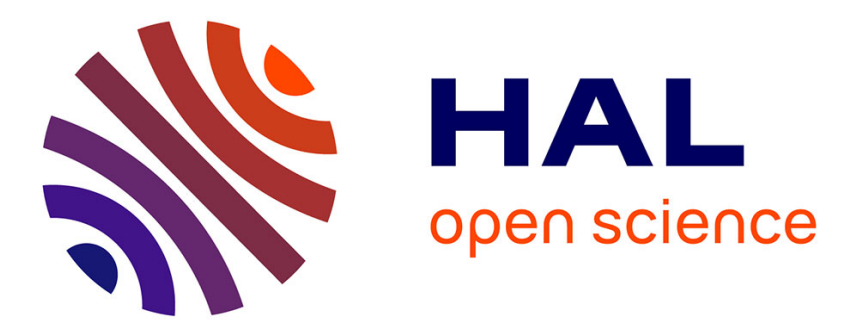

\title{
Nano-droplet ejection and nucleation of materials submitted to non-thermal plasma filaments
}

J.-P. Borra, N. Jidenko, C. Dutouquet, O. Aguerre, J. Hou, A. Weber

\section{To cite this version:}

J.-P. Borra, N. Jidenko, C. Dutouquet, O. Aguerre, J. Hou, et al.. Nano-droplet ejection and nucleation of materials submitted to non-thermal plasma filaments. European Physical Journal: Applied Physics, 2011, 56 (2), pp.24019. 10.1051/epjap/2011110201 . hal-00746219

\section{HAL Id: hal-00746219 \\ https://hal.science/hal-00746219}

Submitted on 28 Oct 2012

HAL is a multi-disciplinary open access archive for the deposit and dissemination of scientific research documents, whether they are published or not. The documents may come from teaching and research institutions in France or abroad, or from public or private research centers.
L'archive ouverte pluridisciplinaire HAL, est destinée au dépôt et à la diffusion de documents scientifiques de niveau recherche, publiés ou non, émanant des établissements d'enseignement et de recherche français ou étrangers, des laboratoires publics ou privés. 


\title{
NANO-DROPLET EJECTION AND NUCLEATION OF MATERIALS SUBMITTED TO NON-THERMAL PLASMA FILAMENTS
}

\author{
Jean-Pascal Borra, N. Jidenko, C. Dutouquet ${ }^{1}$, O. Aguerre ${ }^{1}$, J. Hou $^{2}$, A. Weber ${ }^{2}$ \\ Laboratoire de Physique des Gaz et Plasmas CNRS-Univ. Paris-Sud, Orsay, F-91405 \\ Supélec, 3 Rue Joliot Curie, Gif-sur-Yvette/, F-91192, France, jp.borra@pqp.u-psud.fr \\ ${ }^{1}$ INERIS Parc Technologique ALATA - BP $N^{\circ} 2,60550$ Verneuil en Halatte, France \\ ${ }^{2}$ Institute for Mechanical Process Engineering, Clausthal Univ. Technol.,Zellerfeld, Germanyy
}

\begin{abstract}
Methods to induce non-thermal atmospheric pressure plasma filaments are presented with related properties for micro, streamer and prevented spark discharges, respectively induced in planar Dielectric Barrier Discharges with one electrode covered by dielectric material (mono-DBD) or point-to-plane Corona.

Two mechanisms of nano-particles formation are depicted from aerosol size distributions and TEM analysis. 0.1 to $10 \mathrm{~mJ}$ prevented spark discharges produce 10$100 \mathrm{~nm}$ droplets ejected from melted craters as well as nucleated primary particles and subsequent $10-100 \mathrm{~nm}$ agglomerates, by nucleation and coagulation in expanding vapors jets. With smaller energy per filament, $0.1-10 \mu \mathrm{J}$ micro-discharges and $0.1-100 \mu \mathrm{J}$ streamers, the initial local vapor fluxes emitted from spots of interaction between plasma filaments and electrodes are reduced. Subsequent smaller primary particle density limits the local coagulation in the vapor plume since $2-10 \mathrm{~nm}$ non-agglomerated crystalline metal nano-particles are produced in mono-DBD with $\mathrm{Au}, \mathrm{Ag}$ and $\mathrm{Cu}$ electrode. Besides, the evolution of the aerosol size from primary nano-particles to agglomerates with transit time, suggests slow coagulation of these primary metal particles in mono-DBD.
\end{abstract}

\begin{abstract}
Aerosol properties depend on the energy per filament and on the electrode. The final size is controlled by plasma parameters and transit time in and after the plasma. The aim is to underline emerging applications of atmospheric pressure plasmas for the production of tailored particles with tunable size, composition and structure with nonthermal plasma filaments to control the resulting properties of nano-powders and materials. Production rates and related energetic yields are compared.
\end{abstract}

\section{INTRODUCTION}

Suspended liquid or solid particles in gases present large interfacial surface per unit gas volume used for heat exchange, filtration and heterogeneous chemistry, as well as for the production of nanoparticles at atmospheric pressure. So-called aerosol processes leading to products from reactants with at least one step including aerosols are cost-effective, environment friendly without liquid by-products and energy efficient. Since, high purity particles, more easily collected from gases than from liquids, are produced, some aerosol processes are scaled-up for daily production of hundreds of tons of $\mathrm{TiO}_{2}$ nano-powders and others are integrated in chemistry, energy, environment and health industry [1-8]. If nano-powders are used to save raw material, size-dependent properties of nano-materials are reported for tailored nano-particles smaller than $50 \mathrm{~nm}$ with mono-dispersed size distributions (geometric standard deviation $<1,2[1])$. Hence, ideal nano-materials production process should control particle size, composition and structure of both primary nano-particles and subsequent agglomerates.

To produce nano-materials, suspended primary nano-particles can only be formed by evaporation of liquid droplets leading to crystallized solute (spray drying) or by condensation of vapors also called gas-to-particle conversion. The so-called homogeneous nucleation occurs in gases when the saturation vapor pressure is overcome (as for crystallization above a saturation solute concentration), when 
vapors are rapidly quenched by the carrier gas. Nucleation is a bottom-up route producing suspended nano-particles with unique composition, generally agglomerated. Indeed, classical nucleation processes such as flames, lasers and plasmas lead to agglomerated primary nanoparticles [1-8].

For physical nucleation of solid materials by cooling of expanding vapour plumes, laser and sparks trigger the saturation and produce nanometre sized particles. In that case, vapours are emitted from solid surface vaporized by short successive interactions between the surface and the laser or the plasma confined in a filament -due to reduced diffusion at atmospheric pressure-. This surface of interaction is hereafter referred to spot with diameters from tenth to hundreds micrometers for plasma filaments. The related high power densities $\left(>10^{12} \mathrm{~W} \cdot \mathrm{m}^{-2}\right)$ lead to concentrations of diffusive primary nano-particles $\left(>10^{8} \mathrm{~cm}^{-3}\right)$ which are favourable for fast coagulation with subsequent formation of agglomerates of primary nano-particles. Mechanisms of vapour formation by ion sputtering and/or evaporation are not addressed here, as already discussed in [7].

In order to limit the coagulation, smaller initial density of nucleated nanoparticles is achieved by reducing the power density in the spot to limit the initial vapour flux from solid surfaces. To do so, non-thermal plasma filaments such as micro-discharges induced in millimetre plane-to-plane Dielectric Barrier Discharges (DBD), as well as more energetic streamer and prevented spark discharges induced in centimetre asymmetric point-to-plane gaps, are used.

This paper focuses on plasma filaments (streamer, prevented spark and micro-discharges) on metal and dielectric oxides, for the production of nanoparticles by non-reactive nucleation in carefully conditioned gas (i.e. without an organic vapour). Other nano-powders production processes by nucleation in thermal sparks [2] or by reactive nucleation in non-thermal plasmas with gaseous precursors, as well as particle processing by injection in non-thermal plasmas for electro-deposition or for functional coatings by post-discharge reactivity [9], or in thermal plasmas for purification and surface coatings [2] are not covered in this paper. For the chemical route of nucleation from gas-phase reactions in DBD, the reader can refer to [7][10][10][12] for gaseous pollution control and to $[1][2][10][10][13][14]$ for the production of pure nano-particles by precursors injection in the plasma. Different means to induce atmospheric pressure plasma filaments are presented with related electrothermal properties in compact, low-cost and simple discharge arrangements for the production of nanoparticles from the surface of a bulk solid material. Nano-particle formation mechanisms are defined from collective on-line aerosol size distribution measurements and TEM analysis. Droplets ejection from melted craters is observed with prevented spark discharges only, whereas local nucleation and coagulation in expanding vapor plumes emitted from spots on surfaces submitted to any plasma filament occur even with less energetic streamers and micro-discharges.

Key parameters of formation and growth of particles by nucleation and coagulation in plasmas are presented. Composition, size and structure of primary nanoparticles and agglomerates are related to plasma parameters, to physico-chemical properties of materials and to transit times in and after the plasma. Finally, production rates, energetic yields and related powders properties are compared.

\section{PRODUCTION MEANS AND PROPERTIES OF NON-THERMAL PLASMA FILAMENTS}

Different non-thermal plasmas can be induced by the so-called streamer discharge with filamentary structures, based on electron avalanches sustained by a high and confined space-charge field [15]. This ionisation wave propagates at some $10^{7} \mathrm{~cm} / \mathrm{s}$ and leads to a conductive plasma filament for a few tens of ns [16]. To maintain the non-thermal state of the plasma filament $\left(\mathrm{T}_{\text {electron }}<<\mathrm{T}_{\mathrm{gas}}\right)$, the transition to thermal spark must be avoided by limiting the current intensity (e.g. $<100 \mathrm{~mA} \mathrm{DC}$ in air at Standard Temperature and Pressure -STP-).

Micro-discharges in AC dielectric barrier discharge (see Figure 1a) are generated using plane-toplane millimeter gaps with a dielectric material inserted between the electrodes or deposited on at least one electrode. The production of metal nano-particles implies to use metal on one side and dielectric material on the other, in so-called mono-DBD. Thin and transient filaments (diameter $\sim 100 \mu \mathrm{m}$, duration $\sim 20 \mathrm{~ns}$ ) are homogeneously distributed in space during half of each half-AC period. Each 
filament can be considered as local ion/electron, excited species and vapors sources. One important feature of these micro-discharge filaments is the constant energy per filament, whatever the applied potential and the frequency in the range $1-60 \mathrm{kHz}$ [17]. This allows one to perform post-discharge macroscopic measurement of aerosol produced by a controlled number of similar plasma filaments to evaluate the production per filament. However, the energy per micro-discharge can be varied from 0.1 to a few $\mu \mathrm{J}$ with the gas composition and density (i.e. with gas temperature at standard pressure), as well as with the specific capacitance of the gap.

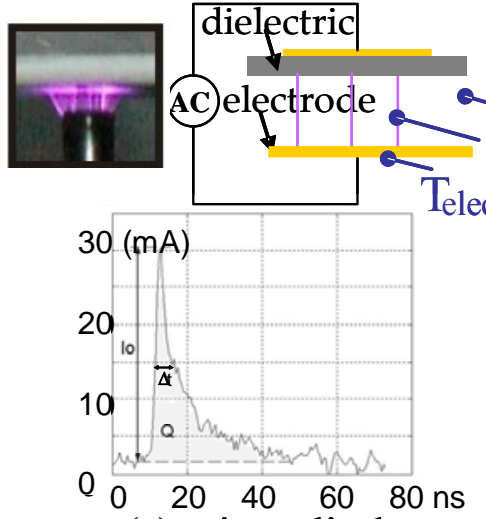

(a) micro-discharge

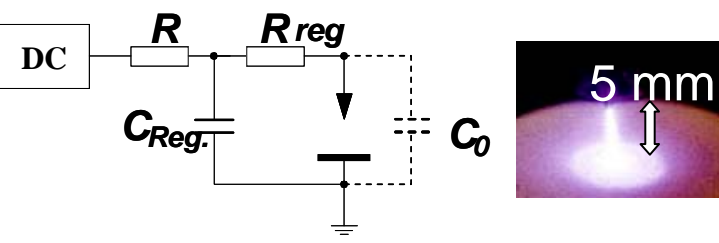

4. re-ionisation 5. Imax

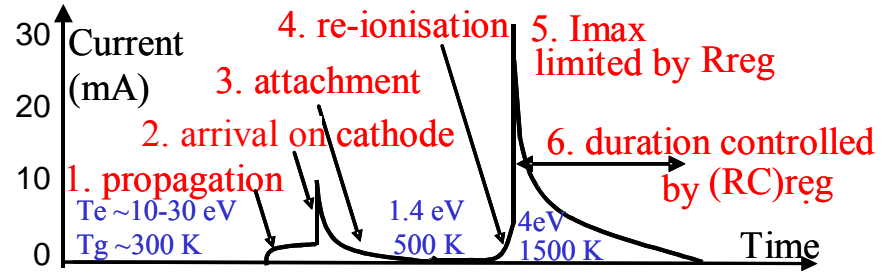

(b) streamer $\stackrel{\text { few } \mu \text { s }}{\longleftrightarrow}$ prevented spark

Figure 1: Pictures, set-ups to induce non-thermal plasma filaments and related current pulses in: (a) microdischarges in plane to plane AC DBD ; (b) Streamer and prevented spark discharge in DC pointto-plane gap $\left(\mathrm{C}_{\text {regulation }}=120 \mathrm{pF}, \mathrm{R}=10^{7}\right.$ and $\left.\mathrm{R}_{\text {regulation }}=5.10^{5} \Omega\right)$ [7]

Streamer discharges can be induced in asymmetric point-to-plane gaps: when the positive sharpest electrode is polarized either in $\mathrm{DC}$ or transiently by a sub- $\mu$ s voltage pulse, shorter than the time required for the streamer-to-spark transition depicted in Figure 1b. Below the spark threshold potential, no spark occurs and successive streamers filaments are developed in the gap. Small $\mathrm{pF}$ gap capacitance limits the energy delivered in the filament which is too small to sustain the formation of a thermal spark. The energy consumption for the streamer development, released from the capacitance ( $\mathrm{C}_{0}$ between the point and all earthed parts), induces a fall of potential. $\mathrm{C}_{0}$ is then recharged by the regulation capacitance. Meanwhile, there is a small increase in the temperature up to a few hundreds of degrees above ambient temperature as mentioned in Table 1. For a given inter-electrodes gap length, the energy per 10 to $100 \mathrm{~ns}$ streamer filament evolves with the potential from 0.1 to $10 \mu \mathrm{J}$ [18].

Prevented spark discharges: above the DC spark threshold potential, thermal sparks develop if the current is not limited. However the current increase and the related thermalisation can be limited with an appropriate external electrical regulation circuit (see $\mathrm{RC}_{\text {regulation }}$ in Figure $\mathbf{1 b}$ ). In that case, the streamer is followed by a prevented spark, depicted in Figure 1b. Indeed, during the dead time between the streamer and the prevented spark, the gas density decreases in the filament, until E/N reaches values which for the ionization dominates over electron attachment. The current and related temperatures of the plasma and probably of the spot strongly depend on impedances $\left(R, R_{\text {regulation }}\right)$ and capacitances $\left(\mathrm{C}_{\text {regulation, }}, \mathrm{C}_{0}\right)$. In such case, the current increase is "fed" by $\mathrm{C}_{\text {regulation }}$ without allowing the spark thermalisation, because the energy stored in $\mathrm{C}_{\text {regulation }}$ is delivered through a control resistance $\mathrm{R}_{\text {regulation, }}$ in the so-called non-thermal prevented spark discharges with energy per filament up to $10 \mathrm{~mJ}$ and neutral gas temperature in the filament below $2000 \mathrm{~K}$ at atmospheric pressure [18][19].

\begin{tabular}{|c|c|c|c|}
\hline & $\begin{array}{l}\text { micro-discharges } \\
\text { in AC DBD }\end{array}$ & \multicolumn{2}{|c|}{$\begin{array}{c}\text { streamer discharges prevented spark discharges } \\
\text { in DC CORONA }\end{array}$} \\
\hline Gap geometry & plane to plane & \multicolumn{2}{|c|}{ point-to-plane } \\
\hline Electrodes & metal + Dielectric mat. & \multicolumn{2}{|c|}{ metal point and metal or dielectric plane } \\
\hline Gap width (mm) & $0.1-$ few $\mathrm{mm}$ & \multicolumn{2}{|c|}{5 to $20 \mathrm{~mm}$} \\
\hline $\mathrm{E}(\mathrm{J}$ per filament $)$ & 0.1 to $10 \mu \mathrm{J}$ & 0.1 to $10 \mu \mathrm{J}$ & 0.1 to $10 \mathrm{~mJ}$ \\
\hline Filament diameter $(\mu \mathrm{m})$ & $<100$ & 10 to few hundreds & 100 to few thousands \\
\hline Plasma Temperature $(\mathrm{K})$ & Tamb. +50 & Tamb. $+[50 ; 400]$ & few thousands $\mathrm{K}$ \\
\hline
\end{tabular}

Table 1: set of properties of non thermal plasma filaments (micro, streamer and prevented spark discharges) 


\section{NANO-PARTICLE PRODUCTION MECHANISMS IN PLASMA FILAMENTS}

\subsection{General set-up and Aerosol measurements}

The experimental set-up is presented on Figure 2. Plasma reactors are fed with 1 to $101 \mathrm{pm} \mathrm{N}_{2}$ at STP. Reactive nucleation from gaseous impurities conversion into condensable species by reactive nonthermal plasmas can be suppressed using filtered dry inert or non-reactive gases. Then whatever 99,99 to $99,999 \%$ purities used, similar aerosol measurements are performed and detected aerosol can only be produced by physical nucleation of vapors emitted from spots of plasma filaments.

Particle size distributions and number concentration: Since, local nucleation and coagulation conditions vary in time and space around each vapor source, collective measurement have to be performed on suspended particles for statistical meaning. The aerosol size distribution is measured on line with a Scanning Mobility Particle Sizer (SMPS) and concentration with a Condensation Particle Counter (CPC), for particles with diameter higher than $3 \mathrm{~nm}$. Both modal diameter (highest concentration per diameter class) and geometric standard deviation of size distribution were measured.

Collection for TEM analysis: The aerosol is collected on TEM grids at $0.3 \mathrm{lpm}$, downstream the plasma aerosol generator by diffusion, thermophoresis and image force during 15 minutes at particle number concentration of $10^{7} \mathrm{~cm}^{-3}$. Indeed, additional characteristics, such as the size of primary nanoparticles and the shape of agglomerates were derived from TEM pictures, the atomic composition from nano-probe EDX and the crystalline structure from Selected Area Electron Diffraction (SAED).

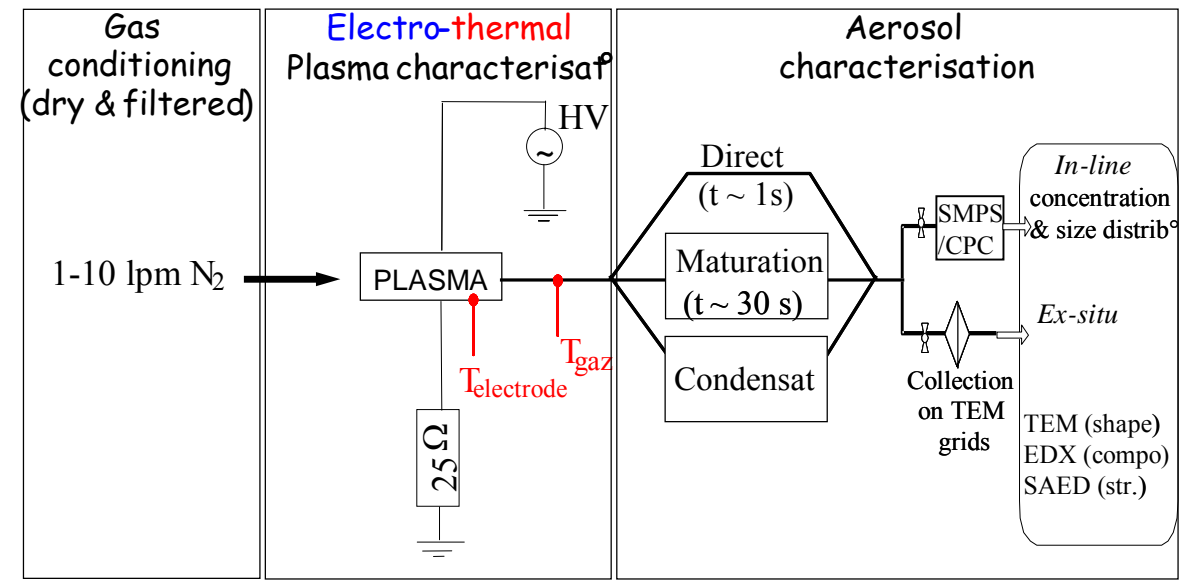

Figure 2 : General set-up for aerosol production studies versus electro-thermal properties of plasma filaments

\subsection{Physical Nucleation and agglomeration in expanding vapor jets/clouds}

It is shown that composition, size and structure of primary nucleated nanoparticles are related to electrode material, plasma parameters and transit times in and after the plasma. The aerosols produced by prevented spark, streamer and micro-discharges filaments are compared.

\subsection{1- DC streamer and prevented spark discharges $\rightarrow$ agglomerated metal nano-particles}

Aerosol size distributions are shown on Figure $3 \mathrm{a}$ for $5 \mu \mathrm{J}$ streamers and for 0.1 to $0.5 \mathrm{~mJ}$ prevented sparks discharges produced in $\mathrm{N}_{2}$ on metals. Both primary nucleated nano-particles smaller than $5 \mathrm{~nm}$ and agglomerates are produced by these plasma filaments, reaching the cathode plane electrode.

Figure $3 \mathrm{a}$ also shows that higher vapor flux, nucleation rate, and local primary nucleated nanoparticles density lead to faster coagulation when primary nano-particle concentration increases with the energy per filament, varying from $5 \mu \mathrm{J}$ streamer to sub-mJ prevented spark discharges.

Finally, EDX analysis confirms that both primary nucleated and agglomerated nano-particles collected downstream the plasma are composed of metal from the electrodes. This confirms the origin of vapors produced by interaction of transient energy flux deposited by plasma filaments on electrode surface.

Properties of primary nucleated nanoparticles produced in $\mathrm{N}_{2}$ can be controlled, since: 
- the nature of the electrode surface controls the final chemical composition of nanoparticles;

- the energy per filament depends on gap geometry, DC applied potential and controls the initial vapor flux from the surface and subsequent diameter and concentration of primary nucleated nano-particles.

The growth dynamic of primary nano-particle into agglomerates is identical to the one that takes place in classical nucleation processes. Indeed, high particle concentration leads to particle growth by Brownian coagulation. As a consequence, the initial bi-modal size distribution of nucleated and agglomerated nanoparticles turns into the so-called unimodal self preserving size distribution, as shown on Figure 3a for higher energy per prevented spark discharge [1][20][21]. Hence, interaction of plasma filaments with surface in pure gases leads to transitory bimodal number size distributions corresponding to nucleation and agglomeration modes. Nucleation occurs close to the vapor source leading to nanometer primary particles, which then coagulate, as recently shown in thermal sparks [6]. Hence, the final size and properties (fractal dimensions and porosity) of agglomerates depend on the initial vapor flux and on the post-production growth and losses in and downstream the plasma reactor.

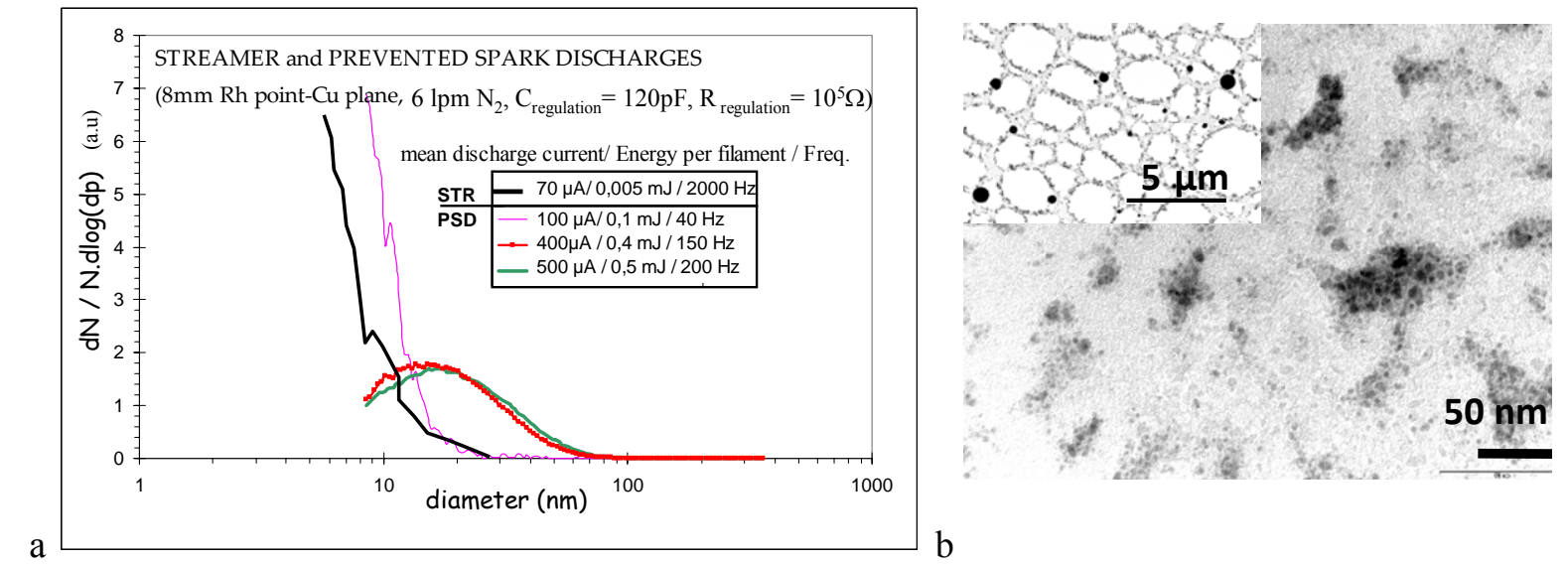

Figure 3 : (a) Particles size distributions from $5 \mu \mathrm{J}$ Streamer and 0.1 to $0.5 \mathrm{~mJ}$ prevented spark discharges (b) TEM pictures of agglomerates of $5 \mathrm{~nm}$ primary particles of copper from the plane and 100 to $500 \mathrm{~nm}$ solidified drops from the rhodium point and from the copper plane produced by prevented spark discharges.

Figure $3 \mathrm{~b}$ and related EDX analysis show 10 to $100 \mathrm{~nm}$ agglomerates of $5 \mathrm{~nm}$ primary particles of copper from the plane with a $20 \mathrm{~nm}$ modal diameter as depicted in the related size distribution in Figure $3 \mathrm{a}$ for $0.5 \mathrm{~mJ}$ prevented spark discharge $(8 \mathrm{~mm}$ gap at $19 \mathrm{kV})$. Figure $3 \mathrm{~b}$ also shows 100 to 500 $\mathrm{nm}$ solidified drops from the rhodium point and from the copper plane. Since there is no shoulder in this size range on the related number size distribution of Figure 3a, the solidified droplets are produced in much lower concentration than the primary and agglomerated nano-particles. The mechanism of production of these bigger nano-droplets is discussed below (cf. § 3.3).

To sum up, the mass per filament of material vaporized from the surface is confirmed to depend on the energy per discharge filament [7]. That is the reason why we focus on the nucleation with «low energy » discharge filaments to reduce the local vapor flux, nucleated primary nanoparticles density and subsequent agglomeration, to prevent the size distribution from enlargement and more dispersed related properties of such nano-powders produced in sparks.

\subsection{2- Micro-discharges $\rightarrow$ Non agglomerated nucleated metal nano-particles}

For micro-discharges from 0.1 to $1 \mu \mathrm{J}$ induced in DBD, the number of filaments per half period, the mean surface temperature and particle concentration increase with voltage at constant energy per filament. Non-agglomerated particles from mono-DBD with gold electrode of a few square centimeters and transit times in the ms range have a mean size of about $4 \mathrm{~nm}$ (cf. Figure 4a). Here, particle size distributions were determined from the TEM images by counting at least 500 particles. The size distribution was fitted with a log-normal distribution to define the modal particle diameter and the geometrical standard deviation $(\sigma)$. From the concentric circles on SAED image, the 2.355 and $2.039 \AA$ lattice constants can be attributed to (111) and (002) reflection planes of crystalline gold. 
(a)
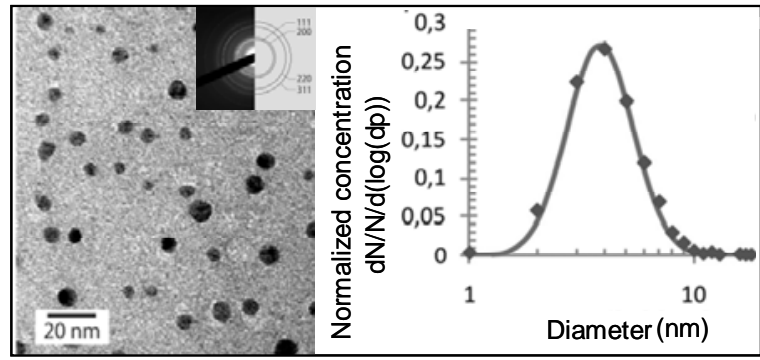

(b)

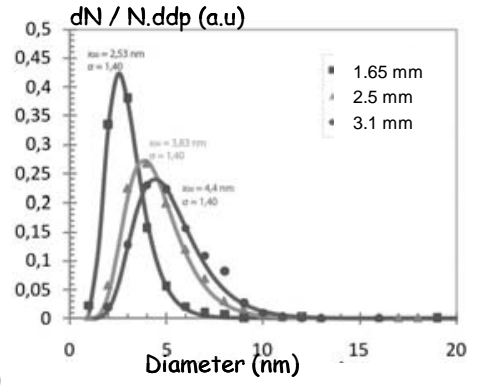

Figure 4: (a) TEM picture of gold nanoparticles produced in mono-DBD (1mm, $70 \mathrm{kHz})$, SAED figure of Au fcc crystalline structure and related size distribution; (b) size distribution versus gap lengths (g)

Figure $4 \mathrm{~b}$ shows particle size distributions from mono-DBD for different gap lengths, normalized for comparison. This normalization consist in dividing the relative density of particles $\mathrm{dN} / \mathrm{N}$, measured for each diameter step $\left(d_{p}\right)$ by the width of the diameter step $\left(d_{p}\right.$ or dlog $d_{p}$ with linear or logarithmic $x$ scales) to prevent from shape modification of the size distribution eventually induced by particles number concentration measurements over different size steps along the size distribution. The modal diameter increases with the gap length, as expected from higher energy per micro-discharge in larger gaps. Hence, the energy per filament in DBD which depends on the gap geometry and dielectric properties (gap length, specific capacitance related to thickness and permittivity of dielectric material [3][9]), controls the local initial vapor flux from surfaces. The mass of material vaporized per filament depends on the energy per filament, for micro-discharges as for streamer and prevented spark discharges, depicted above. In addition, for the same energy per filament, more concentrated aerosols are produced, i.e. the production rate $\left(\mathrm{g} \cdot \mathrm{h}^{-1}\right)$ increases when higher evaporation rates are reached for metals with lower latent heat of vaporization and higher saturation vapor pressure. Hence, alumina nano-particles are produced in mono-DBD with alumina as dielectric material, in much smaller concentration than metal nano-particles, as derived from EDX.

With micro-discharge, the production of non-agglomerated metal nanoparticles has been achieved with different metals at constant energy per filament and number of filaments per half-period in monoDBD of a few square centimeters. Here, primary aerosol is smaller than $5 \mathrm{~nm}$ for gold, silver and copper mono-DBD, supporting that the initial local vapor flux from spots of interaction between plasma filaments and electrodes was successfully reduced using micro-discharges, with subsequent smaller primary particle density which limits the local coagulation.

Final size distributions of the so-formed aerosols also depend on the number of filament per halfperiod, which can be varied within one order of magnitude with the applied voltage and more markedly with the surface of electrodes. Indeed, Figure 5 shows spherical agglomerates with modal diameter from 10 to $20 \mathrm{~nm}$, made of a few $5 \mathrm{~nm}$ primary particles, for transit increased from ms (discussed above for mono-DBD of a few square centimeters) to $50 \mathrm{~s}$ in a $0.25 \mathrm{~m}^{2}$ mono-DBD. This evolution of the aerosol size from primary nano-particles to agglomerates with transit time, suggests slow coagulation of these primary metal particles in mono-DBD. This confirms that agglomeration of less concentrated primary nano-particles can be controlled or even suppressed in "low energy" microdischarge filaments, contrary to streamer and prevented spark discharge filaments, where high initial density of nano-particles and fast agglomeration leads to larger 10-100nm aggregates (cf. figure 3).

(a)

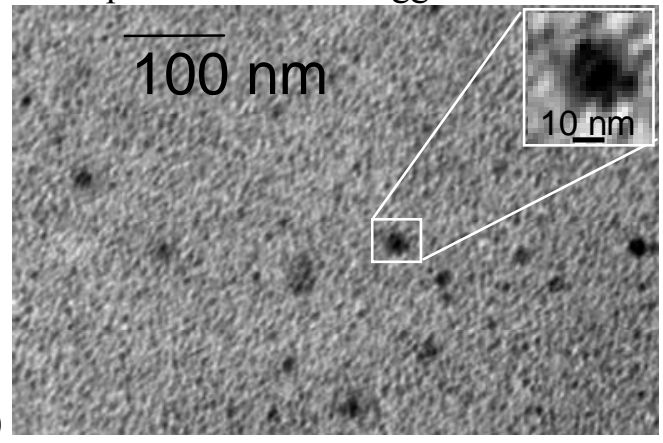

(b)

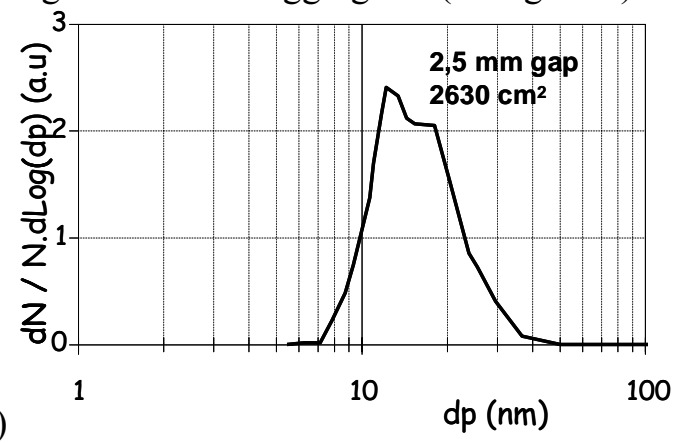

Figure 5: (a) TEM picture of spherical agglomerates and (b) corresponding size distribution of aerosol from mono-DBD with 50s transit time in the large surface mono-DBD at $6 \mathrm{lpm} \mathrm{N}_{2}$. 


\subsection{Prevented spark discharges $\rightarrow$ melted craters and nano-droplet ejection}

With energy ranging from 0.5 to few $\mathrm{mJ}$ prevented spark discharge filaments, sub-micron-sized craters are observed on metal electrode, as depicted in Figure 6a. Droplet ejection mechanism has recently been proposed [22] to account for the 10 to few hundreds nm solidified metal droplet observed on the electrode of prevented spark discharge as well as in the collected aerosol (cf. Figure 3b). Indeed, micro-droplet ejection has been observed from thermal sparks filaments with energy and diameters higher than those of prevented spark discharge filaments. This has been attributed to the recoil force from the solid bottom of the micron-sized crater on melted metal [23]. These spherical solidified drops are much less concentrated than the primary nucleated nano-particles and agglomerates, since there is no shoulder in this size range on the related size distribution of Figure 3a produced by prevented spark discharge, where the modal diameter is related to agglomerates.

(a)

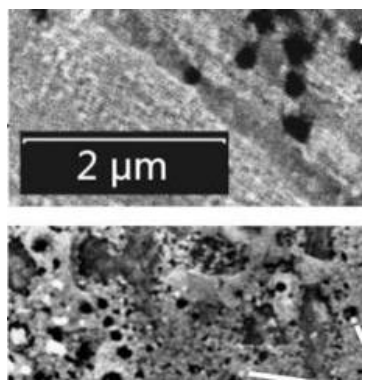

(b)

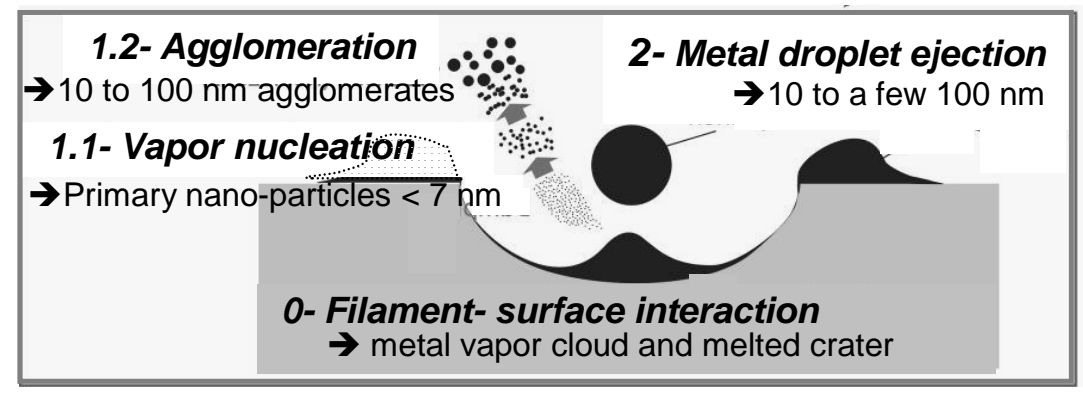

Figure 6 : (a) TEM micrograph of craters formed for 1 (upper) and 60min (lower) of prevented spark discharges on silver electrode; (b) Mechanisms of nucleation/agglomeration and droplet ejection from melted craters formed in spots of interaction between prevented spark discharge and electrode [22-23].

\subsection{Production rate \& cost of nano-powder formation by non-thermal plasma filaments}

Production rates are higher with more energetic prevented spark $(0.1-1 \mathrm{mg} \mathrm{Cu} / \mathrm{h} /$ point $)$ than with micro-discharges $\left(10-100 \mathrm{mg} \mathrm{Cu} / \mathrm{h}\right.$ per $\left.\mathrm{m}^{2}\right)$. Conversely, the energy cost per gram of nano-powder is ten to hundred times higher for prevented spark discharge than for micro-discharges in DBD, but still much lower than for thermal sparks (in the order of J.ng ${ }^{-1}$ ). Indeed, in hotter prevented spark than streamer and micro-discharges, a greater part of the input power is dissipated into gas heating.

As a result, non-thermal plasma filaments may be used as nano-material production processes at reduced energy cost. However, large DBD of few hundreds square meters would be required to reach production rates in the order of g.h $\mathrm{h}^{-1}$. This is not excluded since such production rate is large for nanotechnologies with respect to the added value of nano-products and since large surface mono-DBD exists and may be recycled. Indeed, such industrial mono-DBDs were used until the last decade for ozone production. With electrode surface up-to a few hundreds square meters per system, these industrial mono-DBD ozonizers may be tested for aerosol production processes in pure gases.

Prevented spark discharges also have great potentialities since higher production rates can be reached. Moreover, prevented spark discharges allow one to control accurately the formation conditions (heating/cooling rates and intensities) to study the properties of nano- and agglomerated particles. The possible control of the quality of nano-products (size, composition, crystalline structure of primary particles and agglomeration) by prevented spark discharges may be tested to produce very high added value crystalline metal, dielectric oxides or polymer nanoparticles at atmospheric pressure. Indeed, electro-thermal properties of the prevented spark discharge are controlled by an electrical circuit, the voltage and the gap geometry as well as by the gas flow and injection in the gap, as depicted in $\S 2$.

Finally, the development of nano-material production processes will also depend on the process stability. The issue of electrode material depletion still has to be addressed to keep the electrode position, the gap length and the related electric field, discharge currents and temperatures, as constant as possible with minimum raw material losses. Continuously renewed electrode is already used is commercial spark generator and may be used as well for prevented spark discharges. 


\section{CONCLUSION}

This paper intends to underline emerging applications of atmospheric pressure plasmas for the production of tailored particles with tunable size, composition and structure to control the resulting properties of nano-powders and materials. Indeed, nano-materials with size dependent properties can be produced with non-thermal plasma filaments if fast coagulation is limited either by immediate online post-production processing or at concentration lower than $10^{7} \mathrm{~cm}^{-3}$ :

- The energy deposited in the spot of discharge filaments controls the local vapor flux from each filament (with voltage in asymmetric gap and with gap length in dielectric barrier discharges), the subsequent local particle concentration and the related growth by "fast" agglomeration in the vapor cloud to produce nucleated nano-powders with tailored size.

- Two mechanisms of formation of nano-particles by plasma filaments on metal electrodes have been depicted from aerosol size distributions and TEM analysis of collected particles: 0.1 to $10 \mathrm{~mJ}$ prevented spark discharges produce $10-100 \mathrm{~nm}$ droplets ejected from melted craters as well as nucleated primary particles and subsequent 10 to $100 \mathrm{~nm}$ agglomerates, formed by nucleation and coagulation in expanding vapors jets. With smaller energy per filament, $0.1-10 \mu \mathrm{J}$ micro-discharges and $0.1-100 \mu \mathrm{J}$ streamers, the initial local vapor fluxes emitted from spots of interaction between plasma filaments and electrodes is reduced. Subsequent smaller primary particle density limits the local coagulation rate in the vapor plume since $2-10 \mathrm{~nm}$ non-agglomerated crystalline metal particles are produced in mono-DBD of a few square centimeters with $\mathrm{Au}, \mathrm{Ag}$ and $\mathrm{Cu}$. Besides, 10 to $20 \mathrm{~nm}$ agglomerates may be formed by slow coagulation by increasing the transit time in larger monoDBD. Hence, aerosol with narrow size distribution can be produced at atmospheric pressure by non-thermal plasma filaments to reach size-dependant properties of nano-materials with high specific surface area of any composition (polymer, multi-metal oxides, nitrides, carbides and borides).

An interesting feature of prevented spark discharge is that thermal gradients around each filament can be tuned to define the cooling rate of vapors and the structure of the primary nano-particle (e.g. with spark in water [10]). More generally, new non-thermal plasmas, such as the micro-hollow cathode, have been developed in the last decade and may be used to reach higher production rates in more homogeneous and larger plasma volumes. Besides, RF and micro-wave plasmas at atmospheric pressure may also be investigated for high production rate of nano-powders.

\section{REFERENCES}

[1] T.T. Kodas and M. Hampden-Smith, Aerosol Processing of Materials (New York: Wiley-VCH) (1999)

[2] M. Boulos and E. Pfender, MRS Bull. 21-8, 65-8 (1996)

[3] P.J. Dekkers and K. Friedlander, J. Colloids and Interface Science 248, 295 (2002)

[4] H. Horvath and M. Gangl, J. Aerosol Science 34, 1581 (2003)

[5] N. Jidenko and J-P. Borra, J.Phys. D:Appl. Phys 39-2, 281 (2006)

[6] J.H. Byeon, J.H. Park, J. Hwang, Aerosol Science 39-10, 888 (2008)

[7] J-P. Borra, Plasma Phys. Control Fusion 50, 124036 (2008)

[8] S. Bau, O. Witchger, F. Gensdarmes, D. Thomas, J-P. Borra, J. Nanopart. Research 12, 1989 (2010)

[9] M. Tatoulian, F. Arefi-Khonsari, J. Amouroux, Chem. Materials 18, 5860 (2006)

[10] A. Mizuno, Plasma Phys. Control Fusion 49, 1 (2007)

[11] N. Sano H. Wang, M. Chhowalla, IM. Naito, T. Kanki, Chemical Physics Letters 368, 331 (2003)

[12] E. Odic, L. Parisi, M. Goldman, J.P. Borra,Thermal effect on Plasma Chem. pp 279-312 in Elect.Disch.for Env.Purposes, ed E.M. Van Veldhuizen (NOVA Science Publishers, NewYork, 2000)

[13] N. Jidenko, F. Massines, C. Jimenez, J.-P. Borra, J.Phys. D:Appl. Phys 40 -14, 4155 (2007)

[14] J. Gonzales-Aguilar, M. Moreno and L. Fulcheri, J.Phys. D:Appl. Phys 40, 2361 (2007)

[15] M.Goldman, Corona Discharges, pp 219-215 in Gaseous Electronics, (Ed. N.M.Hirsh, H.J.Oskam,,1978)

[16] C.Heuser, G.Pietsch in IEEE proceedings of the $6^{\text {th }}$ Int. Conf. Gas Discharges, Edinburgh, 1, 98-101 (1980)

[17] M. Petit N. Jidenko J-P. Borra, Rev. Scientific Instrument 73-7 2705-2713 (2002)

[18] E.Marode, S.Samson, D.Djermoune, N.Deschamps, M.Touzeau, A.R.DeSouza, J. Adv. Ox. Tech. 4-1, (99)

[19] E.Marode, proceed. of the $2^{\text {nd }}$ Int. Sym. Plasma Technol. Salvador Brazil, (ed. by Chang, 107-12 1997)

[20] K. Willeke and P. Baron, Aerosol Measurement (Ed Nortrand Reinhold, New York, 1993)

[21] W. C. Hinds, Aerosol Technology 2nd edn (Wiley, New York, 1999)

[22] J. Hou, N. Jidenko, J-P. Borra and A. P. Weber, Chemie Ingenieur Technik, (to be published 2011)

[23] E. Gray and J.R. Pharney, Journal of Applied Physics, 45-2, 667 (1974) 